barbitone, diazepam, or paraldehyde are the preferred drugs, because phenytoin may damage the rapidly developing cerebellum at this age. ${ }^{6}$

Why there should be so great a difference in prevalence of neonatal fits between now and some 10 years ago is not clear. Though it is reasonable to expect that improvement in obstetric standards will result in a reduction in the frequency of birth injury, the proportionate differences then and now between fits of early (under 48 hours) and relatively late (over 72 hours) onset may be due to a contemporary increase in frequency of "metabolic" fits (mostly hypocalcaemic). A recently reported study of hypocalcaemic fits, ${ }^{7}$ also from Edinburgh, identifies a male preponderance and an overall concentration in newborn babies born in late winter and early spring. The mothers tended to be older, of higher parity, and of lower social class than controls. While the high phosphate load of cow's milk undoubtedly predisposes to hypocalcaemia, the evidence strongly suggests that some mothers also have incipient vitamin $\mathrm{D}$ deficiency, from which the fetus would also presumably suffer. The possibility that such fits may be increasing in frequency must therefore be viewed with special concern, partly because of the damaging nature of hypocalcaemic seizures and partly because of the malnutrition this implies.

Of the much rarer causes of metabolic fits several are worth mentioning because of the hopeful prognosis if they are specifically identified and treated. They include maternal diabetes, leucine sensitivity, galactosaemia, and fructosaemia as causes of hypoglycaemia; pyridoxine dependency, which can be dramatically cured within minutes if treated early with intravenous pyridoxine, but otherwise is often fatal; and phenylketonuria. Some iatrogenic causes of hyper- and hypo-electrolytaemic fits have been reported, such as inappropriate fluid therapy and the mistaken substitution of salt for sugar in feeds. ${ }^{6}$ Withdrawal fits from heroin, morphine, barbiturates, or alcohol should not present diagnostic difficulties if the mother's addiction is recognized but may be easily overlooked in abandoned infants.

1 Brown, J. K., Cockburn, F., and Forfar, J. O., Lancet, 1972, 1, 135. 2 Minkovski, A., and Sainte-Anne-Dargassies, S., L'Evolution Psychiatrique,

1956, 1, 279.
3 Keen, J. H., and Lee, D., Archives of Disease in Childhood, 1973, 48, 542.

3 Keen, J. H., and Lee, D., Archives of Disease in Childhood, 1973

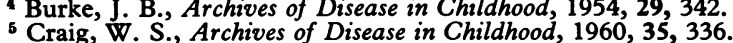

- Craig, W. S., Archives of Disease in Childhood, 1960, 35,

7 Roberts, S. A., Cohen, M. D., and Forfar, J. O., Lancet, 1973, 2, 809.

8 Purvis, R. J., et al., Lancet, 1973, 2, 811.

\section{New Assays for Old}

Relatively specific bioassays for the peptide hormones have existed for many years but they generally suffer from the same disadvantage-namely, lack of adequate sensitivity. This is especially true when attempts are made to assay the hormones in the circulation.

With the advent of radioimmunoassay in the last ten years this problem seemed solved and the advanced technology which evolved has spread from peptide hormone measurements to other hormones such as steroids, which though not intrinsically antigenic can be made so by conjugation with polypeptide or protein molecules. Radioimmunoassay has also been applied to other fields such as oncology, clinical pharmacology, haematology, and microbiology, and possibly the greatest potential of this powerful analytical tool may lie in such non-endocrine subjects. The principles, practice, and clinical applications of radioimmunoassay have now been clearly reviewed in the January number of the British Medical Bulletin, and this will be a most useful reference for clinicians and laboratory workers interested in measurement of natural or synthetic compounds in biological systems. However, in endocrinology, further experience has shown that the increased sensitivity of radioimmunoassay is still not always sufficient. A more important disadvantage is that the immunoreactive material detected in the plasma or tissue may not be biologically active, since the requirements for immunoreactivity rarely coincide with those for biological potency. This has been well shown for ACTH.1 2 The results of radioimmunoassay therefore usually overestimate the concentrations of the true biologically active hormone.

Because of these limitations the successful application of the principles of cellular biochemistry to the measurement of hormone concentrations by J. Chayen and Lucille Bitensky at the Kennedy Institute of Rheumatology, London, has evoked great interest. At a recent symposium ${ }^{3}$ the development and potential of these assays were reviewed. Chayen and Bitensky and their colleagues have shown that, if a specific intracellular biochemical process can be found which is dependent on the concentration of the hormone, then minute amounts of that hormone can be detected with satisfactory precision and specificity.

The first, and best validated, of these assays is for ACTH. Slices ${ }^{4}$ or sections ${ }^{5}$ of guinea-pig adrenal glands are incubated in ascorbate-enriched culture medium for five hours to stabilize the tissue and rid it of the effects of the animal's own hormonal influences. Then the tissue is exposed for only four minutes to the diluted plasma or ACTH standards. The ACTH initiates, in proportion to the concentration of added hormone, the biological processess which lead to steroidogenesis. The limit of detection of the assay is impressively low, $5 \mathrm{fg} / \mathrm{ml}$ ACTH ( 1 femtogram is $10^{-15} \mathrm{~g}$ ). This is one thousand times more sensitive than radioimmunoassay of ACTH, yet it has the further advantage that the results probably reflect the true steroidogenic potency of the ACTH. ${ }^{6}$ ?

As a result of the great sensitivity, plasma to be assayed can be diluted a hundred or a thousand times instead of concentrated from large volumes. ACTH can be estimated in heelprick blood samples from babies, in patients with hypopituitarism, or in normal persons after the administration of large amounts of hydrocortisone. ${ }^{7}$ Under the latter conditions ACTH circulates in a concentration of only a few femtograms per ml, though this still represents many thousand molecules per $\mathrm{ml}$. This is the most sensitive assay for any hormone at present available.

A similar "redox" type of assay for luteinizing hormone has recently been described. ${ }^{8}$ Conventional bioassays cannot reliably measure circulating levels of luteinizing hormone, and radioimmunoassays as indicators of biological potency are unreliable. When validated as a true reflector of the hormone's activity the redox assay should allow subnormal and prepubertal levels to be studied.

Even more impressive is the application of cytochemical techniques to the bioassay of thyrotrophin and the long-acting thyroid stimulator (LATS). These alter lysosomal membrane permeability in thyroid follicular cells. The permeability can be measured because it makes available intralysosomal enzymes. ${ }^{9}$ Instead of the usual bioassay limit of detection for thyroid-stimulating hormone (TSH) of about $100 \mu \mathrm{U} / \mathrm{ml}$, levels often not achieved in the plasma even in myxoedema, this system can detect TSH activity in concentrations as low 
as $0.0004 \mu \mathrm{U} / \mathrm{ml}$ and seems to be similarly sensitive to LATS but with a different time course. Plasma gastrin activity can be bioassayed by the induced stimulation of carbonic anhydrase in the parietal cells of the fundus of the stomach of guinea-pigs, and the assay has a sensitivity equivalent to $5 \mathrm{fg} / \mathrm{ml}$ of pentagastrin.

The principles explored by these new. cytochemical techniques for hormone bioassay are of fundamental importance and we shall see their rapid application to the measurement of many hormones as well as other biologically active substances for which bioassays or radioimmunoassays do not exist or are unsatisfactory.

\footnotetext{
' Besser, G. M., et al., fournal of Clinical Endocrinology and Metabolism, $1971,32,595$.

2 Matsuyama, H., Harada, G., Ruhmann-Wennhold, A., Nelson, D. H. and West, C. D., Fournal of Clinical Endocrinology and Metabolism, 1972 34, 713 .

3 Proceedings of symposium to be published in Clinical Endocrinology.

4 Chayen, J., Loveridge, N., and Daly, J. R., Clinical Endocrinology, 1972, 1,219 .

5 Alaghband-Sadeh, J., Annals of Clinical Biochemistry (in press)

6 Rees, L. H., et al., Nature, New Biology, 1973, 241, 84.

' Rees, L. H., et al., Nature, New Biology, 1973, 241, 84.

8 Rees, L. H., Holdaway, I. M., Kramer, R., McNeilly, A. S., and Chard, R., Nature, 1973, 244, 232.

9 Alaghband-Zadeh, H., Bitensky, L., Daly, J. R., Lawton, N., and Chayen, J., Acta Endocrinologica, 1973, Suppl. No. 177, p. 165.
}

\section{The Rival World}

"Wherever man grows food insects are there to profit by his labours and wherever he stores his crops he will find insects are waiting for their share." These are the opening words of the Shell Film Unit's magnificent film of 1955 when there was so much hope that chemical pesticides could restore to man the third of his crops which the insects of the "rival world" were destroying. Today more than 300 insect species have already become resistant to these chemicals and the additional contribution which pesticides make to environmental pollution cannot be ignored. A joint party of experts from the Food and Agriculture Organization and the World Health Organization have recently considered an alternative method-namely, the use of viruses that kill insects. ${ }^{1}$

Two groups of viruses, those of nuclear polyhedrosis and granulosis, show considerable promise as selective control agents, and some of the former have already been licensed for temporary use in the U.S.A. There is no suggestion that such viruses, however specific, would be alone sufficient to control a pest, and other integrated measures must be used. Further research must take into account two desiderata. The first is that the virus must not infect or harm domestic or wild animals, plants, or man, nor must it be able to mutate to become a harmful virus. All countries proposing to use these viruses should set up a control authority to regulate which viruses are developed and how they should be used. This safety testing must be taken from the laboratory, where the initial studies can be made, to field trials, where the total impact of the virus on the fauna and flora of the area surrounding the treated area can be tested. An important implication in such a trial is that the base-line situation should have been recorded in terms of the target insect species, its predators, and pathogens-the whole ecological net. Virus is a self-multiplying pesticide, and, though in theory it may be possible for a farmer to collect this year's virus-filled corpses to store for next year's application, in practice this will inevitably lead to ecological calamity.

Secondly there must be research to find, evaluate, and develop viruses to control insects important in human and veterinary medicine, and especially those for which the insect vectors are already becoming resistant to chemical pesticides. The working party considered that priority should be given to virological means of controlling the desert locust, the principal pests of stored products, and the stem-borers of rice and maize. It also recommends that infection-free insect colonies should be established and that any insect cell lines which may be set up for production purposes should be free of extraneous micro-organisms.

The U.S. Department of Agriculture Protocols for Safety are detailed in Annex 2 and encompass acute and chronic oral toxicity for rats, dermal toxicity for guinea-pigs, eye and skin irritation for rabbits, and acute inhalation toxicity. The U.S Environmental Protection Agency is concerned about longterm studies (for carcinogenicity), replication in mammalian cells, immunogenicity, mutation, and toxicity to beneficial organisms such as bees, fish, birds, and plants.

It is difficult to see how these various stages in developing a virus as a control agent can be covered in less than five or six years. The experts who produced this report will be encouraged by the F.A.O. and W.H.O. to remain in liaison so that the development of viruses for insect control can be kept under review within the context of an integrated programme for the worldwide control of pests. 1 The Use of Viruses for the Control of Insect Pests and Disease Vectors:
Report of a Joint F.A.O./W.H.O. Meeting on Insect Viruses. WHO Technical Report Series, 1973, No. 531, pp. 1-48.

\section{Commonwealth Foundation}

Quietly, since 1966 the Commonwealth Foundation has established itself as one of the small number of international agencies of real practical value. It was set up to encourage and assist movement of professional men and women within the Commonwealth, and in eight years it has supplied travel grants for nearly two thousand individuals as well as supporting the Commonwealth Medical Association and similar associations for 14 other professions including lawyers, nurses, and pharmacists. Medicine and professions ancillary to medicine have received over $£ 200,000$ in grants out of a total of $£ 1 \frac{1}{2}$ million.

The foundation's income has come mainly from subscribing governments, now totalling 30 ; though in the last three years it has raised some funds from the private sector. It is not an aidgiving agency, and perhaps its outstanding achievements have been its provision of financial help to individuals and the sponsorship of international conferences; yet about one third of its recent expenditure has been on the professional associations. In its current report the foundation firmly rejects the idea that seven years should be the upper limit for a trust to support an organization. "As a relative latecomer to the field of philanthropy," says the report, the foundation "has been able to spot the numerous white elephants languishing on the horizons of the newer world-languishing simply because some Trust or agency has, with the best of original intentions, launched a major scheme only to withdraw support those few vital years before the project could become selfsustaining." At the same time it is clear that the foundation will be able to enlarge the scope of its work only if the more firmly established professional groups become self-sufficient as soon as reasonably possible.

The Commonwealth Foundation Report IV fuly 1971-fune 1973. London, Commonwealth Foundation, 1973. 